\title{
PAIN CAUSED BY EAR TAGGING IN KIDS OF NATIVE BLACK GOATS
}

\author{
Hawar M.H. Zebari ${ }^{\text {a*}, ~ H o g e r ~ M . ~ H i d a y e t ~}{ }^{\mathrm{b}}$, Assel A. I. Al-Naqshabendy ${ }^{\mathrm{c}}$, Nizar J. Hussein ${ }^{\mathrm{d}}$ and Nawroz A. Kakarash ${ }^{\mathrm{e}}$ \\ ${ }^{\text {a }}$ Dept. of Animal Production, College of Agricultural Engineering Sciences, University of Duhok, Kurdistan Region, Iraq- \\ hawar.mikahil@uod.ac. \\ ${ }^{b}$ Dept. of Pathology and Microbiology, College of Veterinary Medicine, University of Duhok, Kurdistan Region - Iraq \\ ${ }^{c}$ Dept. of Medicine and Surgery, College of Veterinary Medicine, University of Duhok, Kurdistan Region of Iraq. \\ ${ }^{\mathrm{d}}$ Dept. of Environmental Sciences, Faculty of Science, University of Zakho, Duhok, Kurdistan Region - Iraq. \\ ${ }^{\mathrm{e}}$ Dept. of Anatomy and Pathology, College of Veterinary Medicine, University of Sulaimani, Kurdistan Region - Iraq.
}

Received: Nov., 2020 / Accepted: Feb., 2021 / Published: Mar.,2021

https://doi.org/10.25271/sjuoz.2021.9.1.781

\begin{abstract}
:
There is no study about changes in behaviour and peripheral temperature of kid goats undergoing ear tagging procedure. This study was designed to elucidate that pain caused by ear tagging affects peripheral temperatures and behavioural observations in Karadi kid goats. Nineteen native black goat kids, aged 10-14 days, were used in this study. Eye and nasal temperatures were recorded before the ear tagging process, and after ear tagging 5 periods in 30 minutes. Besides, the researchers observed each kid's behaviour for 30 minutes before ear tagging and 30 minutes after it, using focal sampling method and the data recorded with instantaneous time sampling to measure the duration and frequency of each behaviour of the kids. Results revealed that peripheral temperatures were significantly decreased for both eye $(\mathrm{P} \leq 0.01)$ and ear $(\mathrm{P} \leq 0.01)$ after ear tagging. The temperatures of both eye and ear decreased after tagging significantly $(\mathrm{P} \leq 0.01)$ for 30 minutes. The proportion of time kid goats spent normal standing and suckling the dam's teat decreased whereas the proportion of time spent head-shaking increased after tagging. Significant differences were found between abnormal standing $(\mathrm{P} \leq 0.01)$ and vocalization $(\mathrm{P} \leq 0.01)$. It is concluded that ear tagging causes a considerable pain in kid goats and using surface temperatures and behaviour are useful indicators to approve it.
\end{abstract}

KEYWORDS: Pain, Goat's kid, Peripheral temperatures, Behaviour, Ear tagging.

\section{INTRODUCTION}

The pain is aversive and it should be mitigated otherwise it will cause sever stress that causes physical and mental suffering (Flecknell et al., 2011; Norring et al., 2014). There are several physiological changes related with pains, are principally caused by two interrelated mechanisms: first, pain is strong stressor that stimulates directly the releasing of hormone from the hypothalamic pituitary adrenal (HPA) axis in mammals, and the second, the damages of body tissues can activate the immune system and hen release different inflammation mediators, hence, the HPA axis could be activated (Prunier et al., 2005). Brain activity, such as electroencephalography, and the concentrations of inflammatory marker in blood such as Interleukin-1; the activity of autonomous nervous system (ANS), for example, heart respiration rates, blood pressure, the diameter of eye pupil, muscle tremor, sweating and body and/or eye temperatures can indicate pain as well. The assessments of ANS activity, surface temperature is, at this time, frequently used to indicate pain (Ghassemi Nejad et al., 2014).

Young farm mammals, such as kid goats and lambs, are exposed routinely to the painful husbandry procedures such as tail docking and ear tagging, and these procedures cause pain to the animals (Guesgen et al., 2016; Hempstead et al., 2017, 2018). Pain in animals causes increases in cortisol hormone concentrations, increases in core body temperature in which reduces peripheral temperature and affects the animal's behaviour (Molony et al., 2012; Hussein and Hidayet, 2019). Understanding the animal behaviour is a crucial tool, not only for the production of an animal, but also, for the animal welfare assessment (Broom, 2009). Together with the physiology of stress, the study of animal behaviour, also called ethology, emerged as a new field of basic science in the middle of the 20th century. Since, behavioural meanings have allowed scientists to assess the animal welfare. Researchers consider the records of animal behaviour as general indicators and the frequent used index for animal pain (Prunier et al., 2013).

Previous studies have explored the effect of pain on animals' behaviour (Keating et al., 2012; Dalla Costa et al., 2014; Ellen et al., 2016). The painful husbandry procedures also lead to animals expressing some abnormal behaviours such as foot stamping, head turning and shaking and abnormal standing (Molony et al., 2012; Hempstead et al., 2017). In addition, pain caused by ear tagging affects the ear movement of kid goats (Hussein and Hidayet, 2019).

Hussein (2015) showed that abnormal behaviours such as foot stamping and abnormal standing and lying are expressed by lambs after two bloodless castration methods. Also, it was revealed by Molony et al. (2012) that head turning, vocalization, tail wagging, restlessness and foot stamping are increased in lambs after the application of castration. Recently, there is a growing interest in using a face grimace scale and changes in ear postures to determine pain and diseases in farm animals (Mc Lennan et al., 2016; Guesgen et al., 2016; Hussein and Hidayet, 2019). Focusing on peripheral temperatures, many studies use infrared thermometers and thermographics to determine emotions and pain experienced by animals (Proctor and Carder, 2016; Hussein, 2018). Infrared thermographic is non-invasive method and it does not need a researcher to handle the animal and hence does not cause stress to animals. Surface temperatures such as nasal and eye temperatures are decreased after negative

* Corresponding author

This is an open access under a CC BY-NC-SA 4.0 license (https://creativecommons.org/licenses/by-nc-sa/4.0/) 
emotional state and after pain (Proctor and Carder, 2016; Hussein, 2018). However, as far as authors aware, there is no study about changes in behaviour and peripheral temperature of kid goats undergoing ear tagging procedure. Therefore, the present study was designed to show the pain caused by ear tagging using peripheral temperatures and behavioural observations in black native goat kids.

\section{MATERIALS AND METHODS}

The experiment was undertaken between March and April 2019 at the animal production farm of Animal Production Department, the College of Agricultural Engineering Sciences, University of Duhok, KRG.

\subsection{Ethical Considerations}

Animal Ethics Committee of Zakho University approved the procedure of ear tagging as a routine husbandry procedure with its code: AEC-002.

\subsection{Animals and General Care}

In this experiment, nineteen native male black goat kids were used at age $10-14$ days. All kids were singleton and each kid was initially placed in an individual pen $(1.5 * 2 \mathrm{~m})$ with its dam. After birth, dams and kids remained together for 7 days to facilitate both bonding and suckling between them. Thereafter, they moved to individual pens and remained there for the next week to be a habituation period for this study.

\subsection{Ear tagging Procedure}

All nineteen kids were allocated to the procedure of ear tagging. Typical ear tags (Prima Flex Ear Tags, Germany) in Kurdistan Region of Iraq were used for the goat kid identification. The ear tags were applied to kids ears using the pliers in the ear tagging process (Prima Flex Ear Tag Pliers, Kerbl, Germany) to above the center of the left ear of the goat kids and the tag numbers were documented for further identification. First, each kid was separately handled and moved outside its pen. Then, kids were restricted individually to prevent any injuries to their ears when their ears were tagged and ear tags were applied.

\subsection{Data Collection}

2.4.1 Behavioural Observations: Behaviours observed using focal sampling method and recorded with instantaneous time sampling to measure the duration and frequency of each behaviour. Each goat kid was observed individually for 60 minutes; 30 minutes before and 30 minutes after the ear tagging with 2 minutes' intervals. Recorded behaviours are shown in Table (1).

Table 1: The recorded behaviours of kids during the study (Source: Molony et al., 2012; Guesgen et al., 2014).

\begin{tabular}{|c|c|}
\hline Behavior & Description \\
\hline Normal Standing & $\begin{array}{l}\text { Standing, walking and playing, } \\
\text { eating or investigating with no } \\
\text { apparent abnormalities. }\end{array}$ \\
\hline $\begin{array}{l}\text { Abnormal } \\
\text { Standing }\end{array}$ & $\begin{array}{l}\text { Standing or walking unsteadily } \\
\text { sometimes with tail wagging, } \\
\text { walking backwards, walking on } \\
\text { knees, moving forwards with bunny } \\
\text { hops, circling, leaning on a support } \\
\text { or falling. }\end{array}$ \\
\hline Suckling & Milk feeding from dam's teat. \\
\hline Head Shake & Forceful voluntary shake of head. \\
\hline Vocalization & Occurrence of each vocal sound. \\
\hline
\end{tabular}

2.4.2 Peripheral Temperature: The temperature data were recorded with infrared thermometer (Benetech, Inc, USA) with its red laser point. The temperature was measured from the eye and the ear of kid goats before ear tagging procedure. Then, the temperature was directly recorded after ear tagging and for 30 minutes after ear tagging for at the following time points: 5,10 , 20 and 30 minutes. Throughout the procedure, the temperature was scored from the distance of 0.5 to $1 \mathrm{~m}$ as was previously done by Proctor and Carder (2015). The environmental temperature and emissivity might affect the temperature values that were taken by the thermometer. Thus, they were automatically adjusted in the thermometer gun as 0.95 .

\subsection{Data Analysis:}

All data were kept in the spreadsheet of Microsoft Excel and arranged for statistical analysis. Thus, the data were exported to Genstat software program (17th edition) to be analyzed. Residual plots that confirmed by a normality test of Shapiro-Wilk test showed the temperature to be parametric. Therefore, they were analyzed using a one-way ANOVA repeated measures followed by Fisher's Unprotected LSD for determination the comparison among mean values. While, according to the normality test of Shapiro-wilk test showed that the behavioural data were nonparametric and, thus, were analyzed individually using a tworelated sample non-parametric wilcoxons test to obtain the variances between all behavioural observations.

\section{RESULTS}

\subsection{Temperature Data}

A significant difference $(\mathrm{P} \leq 0.01)$ was found in the temperature of the eye before $\left(19.4 \pm 0.3{ }^{\circ} \mathrm{C}\right)$ and after the ear tagging procedure $\left(17.1 \pm 0.2^{\circ} \mathrm{C}\right)$. The eye temperature decreased by 2.4 ${ }^{\circ} \mathrm{C}$ after ear tagging (Figure 1). Similarly, the ear temperature had significantly $(\mathrm{P} \leq 0.01)$ decreased after ear tags (Figure 2$)$. The ear temperature before ear tagging (control) was $17.3 \pm 0.3{ }^{\circ} \mathrm{C}$ and after ear tagging was $14.3 \pm 0.3^{\circ} \mathrm{C}$.

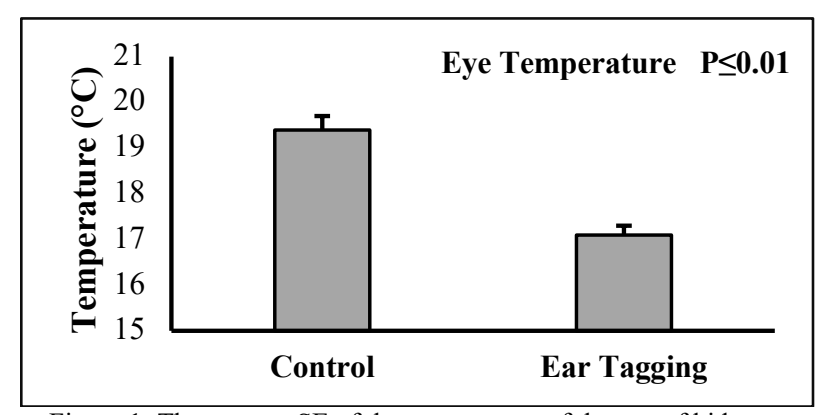

Figure 1: The mean $\pm \mathrm{SE}$ of the temperature of the eye of kid goats before (control) and after the ear tagging procedure.

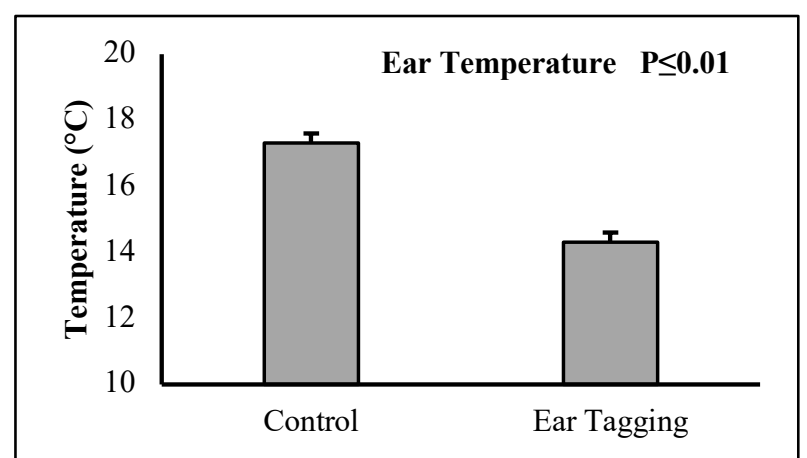

Figure 2: The mean $\pm \mathrm{SE}$ of the temperature of the ear of kid goats before (control) and after the ear tagging procedure. 
It showed in figure 3 that both eye and ear temperatures increased directly after ear tagging application and, then, decreased significantly $(\mathrm{P} \leq 0.01)$ over 30 minutes of recording data.

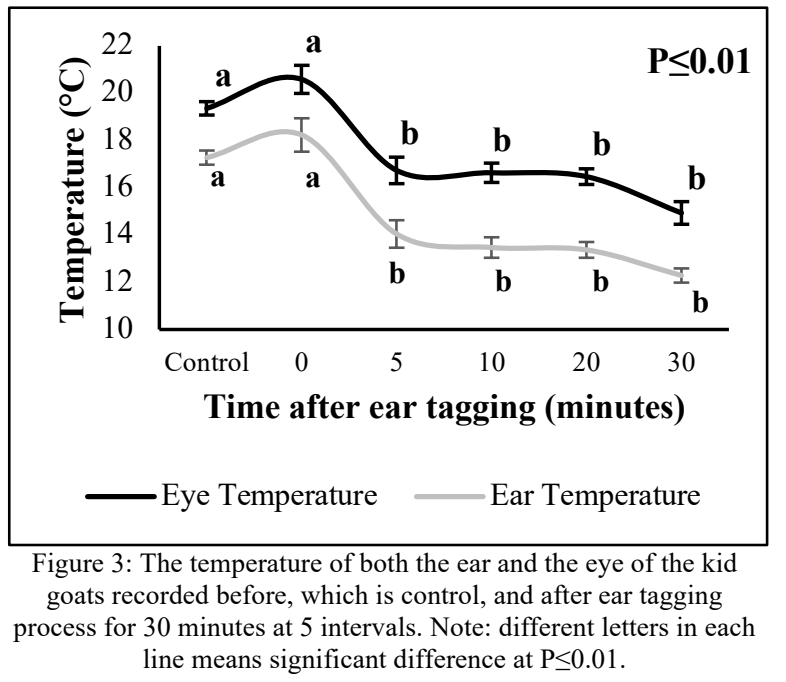

\subsection{Behavioural Data}

The time ratio to spent in each of normal and abnormal standing, head shaking and suckling had shown in Figure 4. The proportion of time kid goats spent normal standing and suckling the dam's teat decreased whereas the time ratio to spent head shaking increased after tagging. In addition, abnormal standing was seen after ear tagging which was absent before the process of tagging.

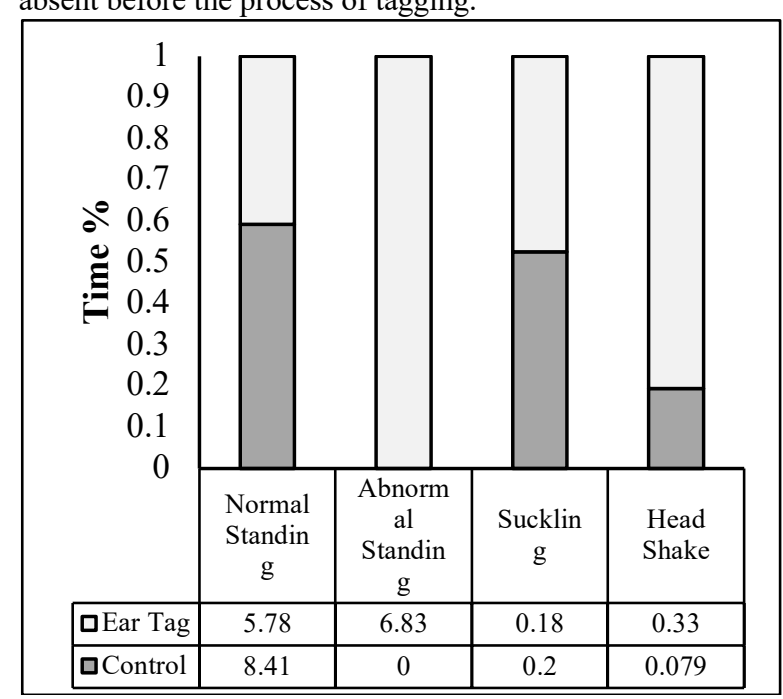

Figure 4: The time percentage that kid goats spent in behaviours of normal and abnormal standing, suckling and head shake before and after the ear tagging procedure.

The box-plots in Figure 5 show the difference between recorded behaviours. Significant differences were found between abnormal standing $(\mathrm{P} \leq 0.01)$ and vocalization $(\mathrm{P} \leq 0.01)$. While there were no differences between suckling, normal standing and head shake were not significant (Figure $5)$.

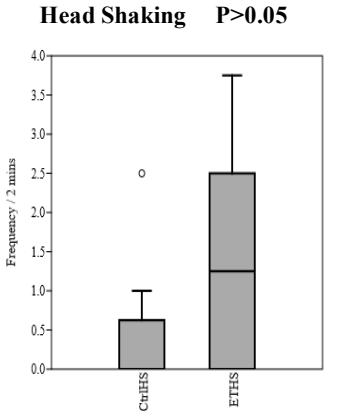

Vocalization $\mathbf{P} \leq \mathbf{0 . 0 1}$

Abnormal Standing $\mathbf{P} \leq \mathbf{0 . 0 1}$
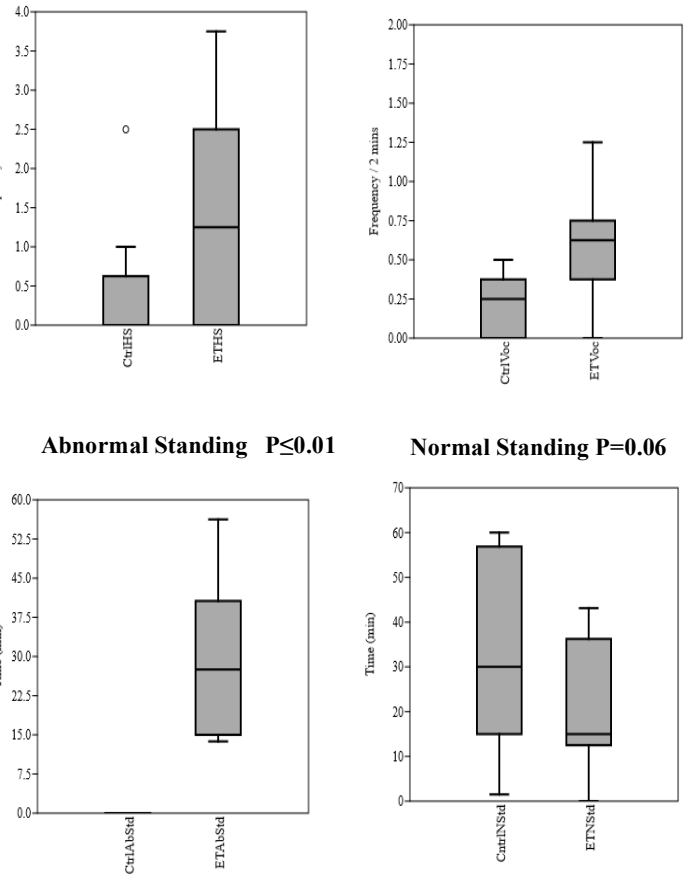

Normal Standing $\mathrm{P}=0.06$

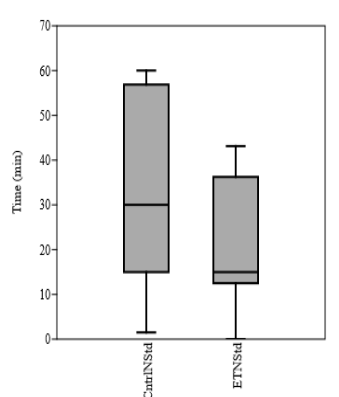

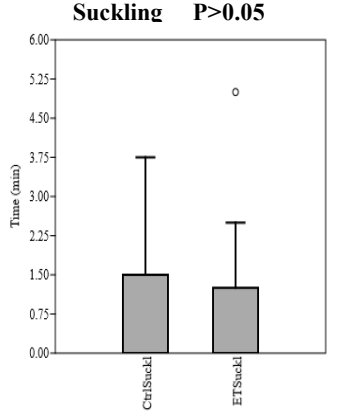

Figure 5: The effect of the ear tagging process on the median time spent and the frequency in each recorded behaviour of black kid goats. Note: moderate outliers are represented as white points. CtrlHS: Control head shake, ETHS: Ear tagging head shake. CtrlVoc: Control vocalization,

ETVoc: Ear tagging vocalization. CtrlAbStd: Control abnormal standing, ETAbStd: Ear tagging abnormal standing. CtrlNStd: Control normal standing, ETNStd: Ear tagging normal standing. CtrlSuckl: Control suckling, ETSuckl: Ear tagging suckling.

\section{DISCUSSION}

The application of ear tagging caused a decrease in both ear and eye temperatures. In addition, ear tagging application affected the behaviour of kid goats in which decreased normal standing and suckling and increased head shake, vocalization and abnormal standing. Other studies have also shown the effects of adverse treatment of peripheral temperatures. Ludwig et al. (2010) undertook a study on rabbits with negative stimuli. They revealed that both ear and eye temperatures significantly decreased following the negative stimuli. Similarly, in a study by Stewart et al (2005), a significant decrease in eye temperature was found in cows following different stressful handling procedures. In addition, the peripheral temperature of cows decreased when offered inedible feed (Proctor and Carder, 2016). In most of previous studies when animal was in pain or a negative emotional state, the surface temperature was decreased (Cabanac and Aizawa, 2000; Stubsjøen et al., 2009; Moe et al., 2012; Proctor and Carder, 2016; Hussein, 2018). The findings of this study of peripheral temperatures are in line with the results of previous studies. The peripheral temperatures of kid goats immediately 
after the ear tagging procedure increased in this study. However, Stewart et al. (2010) found that the peripheral temperature of calves, 20 minutes following castration, increased in contrast to this study, where the peripheral temperatures directly after ear tagging decreased.

Stubsjøen et al. (2009) suggested that using eye temperature to measure peripheral temperature was not an effective technique in ewes. However, they did not find the practical evidence to reject using infrared thermography as an effective instrument to reflect the variability of heart rate in ewes suggesting that eye temperature decreased during moderate pain. Hence, it was recommended by Martins et al. (2013) that infrared thermography is a practical way of diagnosing mastitis and fever detection that was caused by bluetongue virus as an initial sign of the disease in ewes using eye temperature. Additionally, measuring surface temperature was found beneficial to detect emotions and pain of dairy cows (Proctor and Carder, 2016) and sheep (Hussein, 2018). The application of ear tagging did not only affect the peripheral temperature but also affected the behaviour of kids.

It is well-known that painful husbandry procedures such as castration affect the behaviour of animals such as lambs and calves (Molony and Kent, 1997; Molony et al., 2002, 2012; Hempstead et al., 2017). However, less attention has been given to the ear tagging process in the previous research. A recent study by Hussein and Hidayet (2019) showed that ear tagging affects ear postures of kids in response to ear tagging. In this study, changes in behaviours were found after ear tagging. Similarly, changes were reported previously by Molony et al. (2002) who showed that abnormal behaviours, such as restlessness, abnormal standing, statue standing and foot stamping. In addition, lambs castrated with the novel, tighter rubber rings showed pain-related behaviours after castration (Molony et al., 2012). Therefore, the results of this research agree with the previous findings of Molony et al. $(2002,2012)$. In children, pain assessment is mostly based on changes of facial expression, mainly open lips, eyes squeeze, brow bulging and mouth stretch (Stevens and Johnston, 1994). In this study, open mouths, including vocalization, and closed eyes during lying behaviour were the only examples experienced by kids in this experiment. Crying and/or vocalization have been long used as pain indicators in children (Stevens and Johnston, 1994), and in chicken, pigs, sheep and cattle (Prunier et al., 2013). Furthermore, vocalization had shown to be increased in lambs after the castration (Molony and Kent, 1997). Similarly, vocalization significantly increased after ear tagging of black kid goats in the present study.

\section{CONCLUSIONS}

From this study, it is concluded that the application of ear tagging is a painful procedure as it affects the behaviour and the peripheral temperatures of native black goat kids. The changes in behaviour of goat kids after painful procedures like ear tagging were associated with surface temperature decreases when animals experiencing pain after routine procedures; for instance, ear tagging. In addition, measuring peripheral temperatures are useful non-invasive indicators of pain in native black goat kids.

\section{ACKNOWLEDGEMENTS}

The authors would like to thank the staff of the Animal Production Department, College of Agricultural Engineering Sciences, Duhok University. To Assist Prof. Mr. Kawa Yunis Merkhan for his encouragement and support during the practical part of the study. To Dr. Emma Bleach from Harper Adams University, UK, for her support.

\section{REFERENCES}

Andersen, M. L., and Tufik, S. 2003. Sleep patterns over 21-day period in rats with chronic constriction of sciatic nerve. Brain Research, 984(1-2): 84-92.

Broom, D. M. 2009. Animal welfare: future knowledge, attitudes and solutions', In Proceedings AAWS International Animal Welfare Conference (Volume 42), Queensland, Australia, 19.

Cabanac, M. and Aizawa, S. 2000. Fever and tachycardia in a bird (Gallus domesticus) after simple handling. Physiology and Behaiour., 69(4): 541-545.

Cook, N. J., Schaefer, A. L., Warren, L., Burwash, L., Anderson, M. and Baron, V. 2001. Adrenocortical and metabolic responses to ACTH injection in horses: an assessment by salivary cortisol and infrared thermography of the eye, Canadian Journal of Animal Science, 81, 621.

Dalla Costa, E.; Minero, M.; Lebelt, D.; Stucke, D.; Canali, E. \& Leach, M. C. 2014. Development of the Horse Grimace Scale (HGS) as a pain assessment tool in horses undergoing routine castration. PLoS ONE, 9 (3): e92281.

Ellen, Y., Flecknell, P., and Leach, M. 2016. Evaluation of using behavioral changes to assess post-operative pain in the guinea pig (Caviaporcellus).PloS one, 11(9), e0161941.

Flecknell, P., Leach, M., and Bateson, M. 2011. Affective state and quality of life in mice. Pain, 152(5), 963-964.

GhassemiNejad, J., Lohakare, J. D., Son, J. K., Kwon, E. G., West, J. W. And Sung, K. I. 2014. 'Wool cortisol is a better indicator of stress than blood cortisol in ewes exposed to heat stress and water restriction', Animal, 8, 128-132.

Guesgen, M. J., Beausoleil, N. J., Minot, E. O., Stewart, M., Stafford, K. J., and Morel, P. C. H. 2016. Lambs show changes in ear posture when experiencing pain. Animal Welfare, 25 (2): p.171-177.

Guesgen, M. J., Beausoleil, N. J., Minot, E. O., Stewart, M. and Stafford, K. J. 2014. Social context and other factors influence the behavioral expression of pain by lambs. Applied Animal Behavior Science, 159: 41-49.

Hempstead, M. N., Waas, J. R., Stewart, M., Cave, V. M. and Sutherland, M. A. 2018. Evaluation of alternatives to cautery disbudding of dairy goat kids using physiological measures of immediate and longer-term pain. Journal of Dairy Science, 101(6): 53745387.

Hempstead, M. N., Waas, J. R., Stewart, M., Cave, V. M. and Sutherland, M. A. 2017. Behavioral response of dairy goat kids to cautery disbudding. Applied Animal Behavior Science, 194: 42-47.

Hussein, N. J. 2018. Using eye and nasal temperatures to measure positive emotions in free-range hamdani sheep.Basrah Journal Agricultural Sciences, 31(2):24-30.

Hussein, N. J., and Hidayet, H. M. 2019. Changes in Ear Postures of Kid Goats in Response to Ear Tagging.Basrah Journal of Agricultural Sciences, 32(1), 25-33.

Keating, S. C., Thomas, A. A.; Flecknell, P. A. and Leach, M. C. 2012. Evaluation of EMLA cream for preventing pain during tattooing of rabbits: changes in physiological, behavioral and facial expression responses. PloS ONE, 7(9):

Ludwig, N., Gargano, M.; Luzi, F., Carenzi, C. and Verga, M. 2010. Applicability of infrared thermography as a non-invasive measurements of stress in rabbit. World Rabbit Science, 15(4): 199-206.

Martins, R. F. S., Do Prado Paim, T., De Abreu Cardoso, C., Dallago, B. S. L., De Melo, C. B., Louvandini, H. and Mcmanus, C. 2013. Mastitis detection in sheep by infrared thermography. Research in Veterinary Science, 94, 722-724.

Mclennan, K. M.; Rebelo, C. J.; Corke, M. J.; Holmes, M. A.; Leach, M. C. and Constantino-Casas, F. 2016. Development of a facial expression scale using footrot and mastitis as models of pain in sheep.Applied Animal Behavior Science, 176: 19-26.

Moe, R. O.; Bakken, M.; Kittilsen, S.; Kingsley-Smith, H. and Spruijt, B. M.A. 2012. note on reward-related behavior and emotional expressions in farmed silver foxes (Vulpesvulpes) basis for a novel tool to study animal welfare.Applied Animal Behavior Science. 101: 362-368.

Molony, V. and Kent, J. E. 1997.Assessment of Acute Pain in Farm Animals Using Behavioral and Physiological Measurements.Journal of Animal Science, 75, 266-272.

Molony, V.; Kent, J. E. and Mckendrick, I. J. 2002. Validation of a method for assessment of an acute pain in lambs, Applied Animal Behavior Science, 76(3):215-238. 
Molony, V., Kent, J. E., Viñuela-Fernández, I., Anderson, C. and Dwyer, C. M. 2012. Pain in lambs castrated at 2days using novel smaller and tighter rubber rings without and with local anaesthetic, The Veterinary Journal, 193:8186.

Norring, M., Wikman, I., Hokkanen, A. H., Kujala, M. V., and Hänninen, L. 2014. Empathic veterinarians score cattle pain higher. The Veterinary Journal, 200(1), 186-190.

Ohayon, M. M. 2005. Relationship between chronic painful physical condition and insomnia. Journal of Psychiatric Research, 39, 151-159.

Proctor, H. and Carder, G. 2016. Can changes in nasal temperature be used as an indicator of emotional state in cows?.Applied Animal Behavior Science. 184: 1-6.

Proctor, H. S., and Carder, G. 2015. Nasal temperatures in dairy cows are influenced by positive emotional state. Physiology \& Behavior, 138, 340-344.

Prunier, A., Mounier, A. M. and Hay, M. 2015. Effects of castration, tooth resection, or tail docking on plasma metabolites and stress hormones in young pigs. Journal of Animal Science, v.83, 216-222.

Prunier, A., Mounier, L., Le Neindre, P., Leterrier, C., Mormède, P., Paulmier, V., Prunet, P., Terlouw, C. and Guatteo, R.
2013. Identifying and monitoring pain in farm animals: a review', Animal, 7, (06), 998-1010.

Rushen, J., and De Passillé, A. M. 2012. Automated measurement of acceleration can detect effects of age, dehorning and weaning on locomotor play of calves. Applied Animal Behavior Science, 139(3-4),169-174.

Stevens, B. J. and Johnston, C. C. 1994. Physiological responses of premature infants to a painful stimulus .Nursing Research, 43, (4), 226-231.

Stewart, M., Webster, J. R., Verkerk, G. A., Schaefer, A. L., Colyn, J. J. and Stafford, K. J. 2007. Non-invasive measurement of stress in dairy cows using infrared thermography. Physiology and Behavior, 92, (3), 520-525.

Stewart, M., Webster, J. R., Schaefer, A. L., Cook, N. J. and Scott, S. L. 2005.Infrared thermography as a non-invasive

Stubsjøen, S. M., Flø, A. S., Moe, R. O., Janczak, A. M., Skjerve, E., Valle, P. S. and Zanella, A. J. 2009. Exploring non-invasive methods to assess pain in sheep.Physiology and Behavior, 98: 640-648.

Thornton, P. D. and Waterman-Pearson, A. E. 2002. Behavioral responses to castration in lambs', Animal Welfare, v.11, (2), 203-212. 